\title{
The role of B-type natriuretic peptide in the evaluation of congestive heart failure patients in emergency department
}

\author{
Hao Wang*, Tiffany Littleton, Sonya J. Wilson, Ferran Ros, Richard D. Robinson, \\ Kathleen A. Delaney
}

Department of Emergency Medicine, JPS Health Network, Fort Worth, USA

Email: ${ }^{*}$ hwang01@jpshealth.org

Received 29 November 2011; revised 27 December 2011; accepted 16 January 2012

\begin{abstract}
Aim: Congestive heart failure (CHF) is a severe cardiovascular disorder seen in the Emergency Department (ED). B-type Natriuretic Peptide (BNP) is usually ordered to evaluate the CHF severity. However, it is difficult to interpret serum BNP level when different clinical entities existed. The aim of this study is to illustrate the correlation between serum BNP level and relevant clinical variables and further determine the role of serum BNP in different CHF patients. Methods: Univariate comparisons between 26 clinical variables and serum BNP level were analyzed. In order to avoid confounding factors, potential independent clinical variables were analyzed together using multivariate regression. Results: 529 CHF patients were reviewed and divided into different groups by 26 clinical variables. Serum BNP levels were found statistically significant different by univariate compareson between groups divided by 8 clinical variables that included obesity, diastolic/systolic heart failure (HF), serum blood urea nitrogen (BUN) level, serum creatinine (Cr) level, serum sodium (Na) level, patients taking loop diuretics, history of cerebrovascular accident (CVA), and history of dementia. Among all 8 clinical variables, obesity, serum BUN, Cr level, and diastolic/systolic HF had weak-to-moderate correlation effects with serum BNP level by correlation coefficient analysis. However, only obesity and diastolic/systolic HF were two moderately stronger clinical variables that can affect the serum BNP levels by multivariate regression. Analyzing CHF patients separately by obesity and diastolic/systolic HF subsets showed longer hospitalization in diastolic HF patients with relatively higher serum $\mathrm{Cr}$ level. In addition, poor correlation was found between serum BNP level and length of hospitalization $(\mathrm{LOH})$ as well. Conclusion: High variability of serum BNP levels exists in CHF patients with weak-to-moderate correlation effects particularly on obesity and diastolic/systolic HF.
\end{abstract}

${ }^{*}$ Corresponding author.
It is recommended that physicians should be cautious on interpreting BNP in different CHF populations.

Keywords: Congestive Heart Failure; B-Type Natriuretic Peptide; Clinical Variables; Emergency Department

\section{INTRODUCTION}

Congestive heart failure (CHF) is a common disorder seen in the Emergency Department (ED). B-type Natriuretic Peptide (BNP) is one of the common serum markers to evaluate the clinical conditions of CHF patients $[1,2]$. Results from previous studies showed serum BNP levels correlated well with the severity of CHF patients [3]. Patients with higher serum BNP levels required more aggressive treatment and longer hospitalization [4]. However, multiple clinical variables could affect the serum BNP level in CHF patients, making it hard to interpret $[5,6]$. CHF Patients with renal insufficiency tend to have higher serum BNP levels than ones with normal renal functions [7]. Obese CHF patients seem to have relatively lower serum BNP levels than non-obese groups [8]. Diastolic HF patients usually have lower serum BNP levels compared with systolic HF patients [9]. Till now, it is still unclear whether these clinical variables are independent predictors, and to what extent they can affect the serum BNP levels in CHF patients. Hence, to properly interpret serum BNP levels in CHF patients will help ED physician providing appropriate treatment and disposition.

The aim of this study is to evaluate the correlations between serum BNP level and these relevant clinical variables and further help physicians to interpret its variability in different CHF patients.

\section{MATERIAL AND METHODS}

\subsection{Study Design}

Data were collected from patients with history of CHF 
seen in an urban county hospital ED. The diagnosis of CHF was confirmed by cardiologists using echocardiography (at least once in the past 6 month before the index visit) and/or clinical signs and symptoms and was reflected by the discharge ICD-9 code. All eligible male and female adult patients were included. Our population is subject to a high risk of chronic disease exacerbation. Fewer than $2.5 \%$ have commercial insurance. Various factors that include transportation, homelessness, and communication access limit the ability to outpatient follow-up.

Collected data included patient information, past medical history, history of chronic medication, vital signs upon patient arrival in ED, initial electrocardiogram (EKG), initial laboratory evaluation, patient disposition, and length of hospitalization (LOH) if patients were admitted.

Different clinical variables (26 variables) that could potentially affect the serum BNP levels were selected that included age, gender, obesity, vital signs (including heart rate, respiratory rate, blood pressure, and pulse oxymetry), blood urea nitrogen (BUN), creatinine (Cr), sodium $(\mathrm{Na})$, diastolic versus systolic heart failure (diastolic/systolic HF), atrial fibrillation with rapid ventricular response (A-fib with RVR) upon arrival at ED, using long-term angiotension converting enzyme inhibitor (ACEI), beta-blocker, loop diuretics, or digoxin, history of coronary artery disease (CAD), hypertension (HTN), diabetes (DM), chronic obstructive pulmonary disease (COPD), cerebrovascular accident (CVA), hepatic cirrhosis, dementia, cancer, smoking history, and admission to hospital.

Body mass index (BMI) was calculated as weight in kilograms divided by the square of height in meters and was used as an index to evaluate the severity of obesity [10]. CHF patients were divided into four different groups according to their BMI. Group 1 was normal/underweight patients with BMI $\leq 24 \mathrm{~kg} / \mathrm{m}^{2}$, group 2 was overweight patients with BMI $24-30 \mathrm{~kg} / \mathrm{m}^{2}$, group 3 was obese patients with BMI $30-40 \mathrm{~kg} / \mathrm{m}^{2}$ (including $30 \mathrm{~kg} / \mathrm{m}^{2}$ ), group 4 was morbidly obese patients with BMI $\geq 40 \mathrm{~kg} / \mathrm{m}^{2}$. $\mathrm{BNP}$ values were compared among these four groups.

Univariate comparisons between serum BNP and different clinical variables were performed initially. Correlation coefficient was calculated between serum BNP and each clinical variable. Multivariate regression analysis was then analyzed on clinical variables with statistically significant difference found on univariate analysis. Relatively moderate to strong clinical predictors were further selected to evaluate the relationships with serum BNP. This study was approved by the hospital Institutional Review Board.

\subsection{Statistics}

Serum BNP levels were compared in groups divided by different clinical variables using student $t$ test analysis. Correlation between serum BNP level and each clinical variable was measured by correlation coefficient analysis. To compare the serum BNP level in different BMI groups, a one way analysis of variance (ANOVA) using the Bonferroni test was performed. In order to avoid confounding factors, multiple potential independent clinical variables were analyzed using multivariate regression. Beta weights $(\beta)$ were calculated to determine the correlation effect $(\beta$ between 0.2 and 0.5 is considered a moderate effect, and $\beta>0.5$ is considered a strong effect). All statistical analyses utilized Stata 11.0 statistical software (College Station, TX). A $p$ value less than 0.05 was considered to be statistically significant.

\subsection{Results}

Comparison of serum BNP levels in CHF patients grouped with different clinical variables.

From Jan. 2008 till Dec. 2010, a total of 529 CHF patients' clinical data were reviewed. All of these patients were diagnosed as CHF previously. Systolic heart failure (HF) was defined as impaired LVEF $<40 \%$ on echocardiogram and those with reserved LVEF ( $\geq 40 \%$ ) were diagnosed as diastolic HF. In order to determine which variables that can affect the serum BNP level in CHF patients, Serum BNP levels were compared in CHF patients groups with 26 different variables as mentioned in study design. Eight out of 26 variables can affect the serum BNP levels and reached statistically significant difference (see Table 1). Overall, Significantly high difference found on serum BNP levels between patients grouped by 4 clinical variables (obesity, diastolic/systolic $\mathrm{HF}$, serum BUN, and Cr levels). Obese CHF patients had more diastolic heart failure than non-obese patients (55.8\% vs. $43.5 \%, p=0.005)$. They also tended to be younger, with a higher incidence of diabetes (DM) and hypertension (HTN). Obese CHF patients were more likely to be hypoxic and to receive non-invasive positive pressure ventilation (NIPPV) at ED. In addition, serum BNP levels in obese CHF patients were significantly lower compared with those of the non-obese ones $(p<$ 0.001 , see Table 1).

Serum BNP level was inversely proportional to the severity of obesity.

CHF patients were also subdivided into four different groups based on the severity of obesity. Our results showed that the level of BNP was inversely proportional to the severity of obesity in CHF patients, reaching statistically significant difference between groups $(p<$ 0.001, see Figure 1). However, serum BNP level only moderately correlated with the severity of obese in CHF patients $(r=-0.3248, p<0.001)$. This indicates that obesity is not the only variable that can affect the serum BNP level in CHF patients. 
Table 1. Comparison of serum BNP levels between groups with different clinical variables in CHF patients.

\begin{tabular}{|c|c|c|c|}
\hline \multirow{2}{*}{ Clinical Variables } & \multicolumn{2}{|c|}{$\begin{array}{c}\text { Serum BNP Level } \\
(\mathrm{pg} / \mathrm{dl}, \text { Mean } \pm \text { SD })\end{array}$} & \multirow{2}{*}{$\begin{array}{c}\text { Statistical } \\
\text { Significance }\end{array}$} \\
\hline & Yes & No & \\
\hline \multicolumn{4}{|l|}{ General Information } \\
\hline \multicolumn{4}{|l|}{ Age } \\
\hline ( $<40$ year old $)$ & $802.6 \pm 916.8$ & & \\
\hline (40 - 50 year old, not including 50 year old) & $864.4 \pm 847.7$ & & \\
\hline (50 - 60 year old, not including 60 year old) & $979.0 \pm 892.3$ & & \\
\hline (60 - 70 year old, not including 70 year old) & $960.2 \pm 924.0$ & & \\
\hline$(\geq 70$ year old $)$ & $1155.8 \pm 1033.2$ & & $p=0.1877$ \\
\hline Gender (Male-Yes) & $980.2 \pm 899.9$ & $945.5 \pm 939.4$ & $p=0.6660$ \\
\hline Obesity & $688.9 \pm 693.5$ & $1231.2 \pm 1023.3$ & $p<0.001$ \\
\hline \multicolumn{4}{|l|}{ Vital Sign/Physical Examination } \\
\hline Tachycardia (pulse $\geq 100$ beats/min) & $921.8 \pm 844.2$ & $985.7 \pm 951.2$ & $p=0.4521$ \\
\hline Hypertension (BP $\geq 140 / 90 \mathrm{mmHg}$ ) & $1003.2 \pm 967.9$ & $895.8 \pm 816.6$ & $p=0.1962$ \\
\hline Tachypnea $(\mathrm{RR}>20$ times $/ \mathrm{min})$ & $965.2 \pm 939.2$ & $964.3 \pm 904.8$ & $p=0.9911$ \\
\hline Hypoxia (Pox < $94 \%$ on room air) & $851.2 \pm 833.5$ & $987.9 \pm 932.5$ & $p=0.1980$ \\
\hline \multicolumn{4}{|l|}{ Past Medical/Social History } \\
\hline CAD & $1013.6 \pm 949.1$ & $869.6 \pm 846.1$ & $p=0.0870$ \\
\hline $\mathrm{DM}$ & $914.6 \pm 900.7$ & $1014.1 \pm 932.1$ & $p=0.2121$ \\
\hline COPD & $943.5 \pm 877.9$ & $970.5 \pm 928.7$ & $p=0.7798$ \\
\hline Hypertension & $955.2 \pm 933.9$ & $1022.5 \pm 809.7$ & $p=0.5586$ \\
\hline CVA & $664.1 \pm 526.5$ & $990.6 \pm 939.1$ & $p=0.0267$ \\
\hline Cancer & $1136.4 \pm 951.4$ & $951.0 \pm 913.9$ & $p=0.2246$ \\
\hline Hepatic Cirrhosis & $950.1 \pm 641.0$ & $964.9 \pm 922.5$ & $p=0.9578$ \\
\hline Dementia & $1756.8 \pm 1715.8$ & $955.5 \pm 902.9$ & $p=0.0332$ \\
\hline Smoking & $947.4 \pm 905.0$ & $980.1 \pm 929.2$ & $p=0.6825$ \\
\hline \multicolumn{4}{|l|}{ Adjunct Test } \\
\hline EKG (A-fib with RVR) & $748.7 \pm 722.2$ & $982.8 \pm 930.0$ & $p=0.1166$ \\
\hline BUN (>21 mg/dl) & $1255.4 \pm 1085.7$ & $817.2 \pm 779.7$ & $p<0.001$ \\
\hline $\mathrm{Cr}(>1.2 \mathrm{mg} / \mathrm{dl})$ & $1222.5 \pm 1106.1$ & $816.5 \pm 751.1$ & $p<0.001$ \\
\hline $\mathrm{Na}(<135 \mathrm{mg} / \mathrm{dl})$ & $1248.9 \pm 1028.1$ & $926.2 \pm 895.4$ & $p=0.0086$ \\
\hline Echo (Diastolic HF-Yes) & $792.3 \pm 878.2$ & $1133.7 \pm 924.6$ & $p<0.001$ \\
\hline \multicolumn{4}{|l|}{ Disposition in ED } \\
\hline Admission & $978.0 \pm 923.7$ & $817.5 \pm 836.4$ & $p=0.2667$ \\
\hline \multicolumn{4}{|l|}{ Medication } \\
\hline ACEI & $938.9 \pm 856.0$ & $1021.3 \pm 1039.9$ & $p=0.3388$ \\
\hline Beta Blocker & $1002.9 \pm 929.6$ & $811.9 \pm 852.0$ & $p=0.0566$ \\
\hline Loop Diuretics & $1004.4 \pm 931.9$ & $699.6 \pm 766.1$ & $p=0.0099$ \\
\hline Digoxin & $899.9 \pm 673.5$ & $972.1 \pm 941.6$ & $p=0.5808$ \\
\hline
\end{tabular}

Table 1 showed the comparison of serum BNP levels in different groups. Univariate comparisons of serum BNP levels using student $t$ test were analyzed between groups divided by 26 different clinical variables. Results showed eight clinical variables that could affect the serum BNP levels after univariate analy- sis. CHF patients with elevated serum BUN, Cr levels, systolic HF, and non-obesity result in higher serum BNP levels that reached statistical significant difference $(p<0.001)$. Abbreviations: CHF: Congestive heart failure; BNP: B-type natriuretic peptide; SD: Standard deviation; CAD: Coronary artery disease; DM: Diabetes mellitus; COPD: Chronic obstructive pulmonary disease; CVA: Cerebral vascular accident; EKG: Electrocardiography; A-fib with RVR: Atrial fibrillation with rapid ventricular response; BUN: Blood urea nitrogen; Cr: Creatinine; Na: Sodium; Echo: Echocardiography; HF: Heart failure; ACEI: Angiotensin converting enzyme inhibitor; ED: Emergency department.

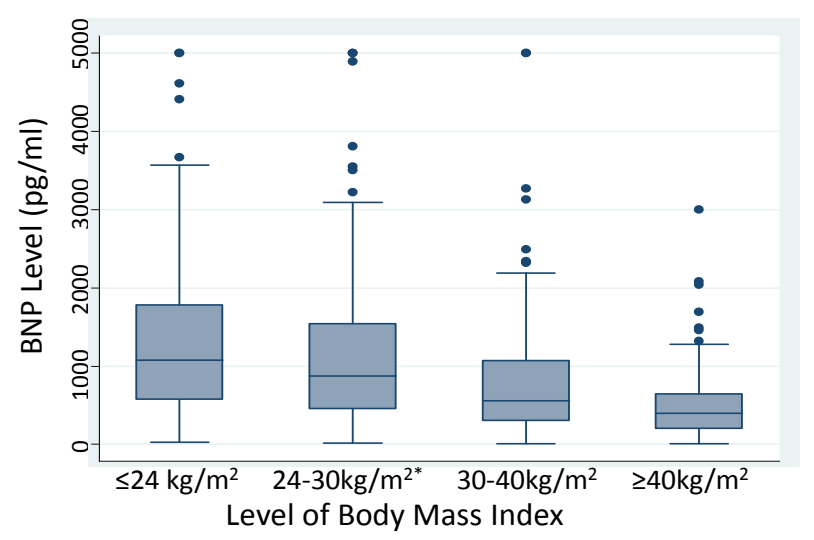

Figure 1. Box plots showed the relationship between obesity and BNP levels. Figure showed that the BNP level was reversely proportional to the BMI level. ${ }^{*}$ BMI not including $30 \mathrm{~kg} / \mathrm{m}^{2}$.
Univariate comparison and multiple regression analysis of serum BNP levels with different clinical variables.

To avoid the confounding factors among independent variables, multiple regression analysis was also performed in these 8 variables to see whether they have strong relationships with serum BNP level in CHF patients. Our results showed serum $\mathrm{Na}$ level had no statistically significant effect and was considered as a confounding factor. History of CVA, dementia, and taking loop diuretics were weak predictors. Serum BUN and $\mathrm{Cr}$ levels had moderate relationships with serum BNP levels in CHF patients. The two clinical variables showing the strongest predictors in this study were: Diastolic vs. systolic heart failure $(\beta=-0.173, p<0.001)$ and obesity $(\beta=-0.257, p$ $<0.001$ ) (see Table 2). 
Analyzing CHF patients separately by obesity and diastolic/systolic HF showed longer hospitalization in diastolic $\mathrm{HF}$ patients with relatively higher serum $\mathrm{Cr}$ levels.

Since diastolic vs systolic heart failure and obesity are two clinical variables that had relatively stronger relationships with serum BNP level. Further analysis was performed by subdividing CHF patients into four different groups (obese diastolic HF, obese systolic HF, non-obese diastolic HF, and non-obese systolic HF groups). Due to moderate predictive effects on BNP levels, serum BUN and $\mathrm{Cr}$ levels were also included in this analysis. Previous studies showed that the level of BNP was associated with the severity of CHF and could possibly affect the LOH [11]. Our results showed diastolic HF patients including both obese and non-obese patients had relatively higher serum $\mathrm{Cr}$ level and tended to stay longer in hospital than systolic HF patients though no statistically sig- nificant difference reached (see Table 3). Statistically significant difference found on serum BUN levels in different groups and diastolic HF patients tended to have higher serum BUN level than systolic HF patients which was also consistent with the findings of serum $\mathrm{Cr}$ level. There were strong linear correlation between serum $\mathrm{Cr}$ and BNP levels in diastolic HF patients. However, very poor correlations were found between serum BNP and LOH in all four groups (see Table 3). Multiple regression analysis was again performed in these four different groups with six clinical variables (serum BUN, Cr, Na level, history of CVA, dementia, and taking loop diuretics). Our results showed only serum $\mathrm{Cr}$ level had moderate correlation effect with serum BNP levels in both diastolic obese CHF $(\beta=0.4046, p<0.001)$ and diastolic non-obese CHF groups $(\beta=0.2418, p=0.047)$, which were consistent with the results of correlation coefficient analysis.

Table 2. Correlation coefficient and multivariate regression analysis of clinical variables that affect serum BNP levels in CHF patients.

\begin{tabular}{ccc}
\hline Clinical variables & Correlation coefficient $(r)$ & Beta weights $(\beta)$ \\
\hline History of CVA & $-0.096(p=0.027)$ & $-0.094(p=0.017)$ \\
History of dementia & $0.0926(p=0.033)$ & $0.090(p=0.023)$ \\
Taking loop diuretics & $0.1120(p=0.010)$ & $0.092(p=0.020)$ \\
Serum BUN level & $0.2736(p<0.001)$ & $0.136(p=0.007)$ \\
Serum Cr level & $0.2321(p<0.001)$ & $0.137(p=0.005)$ \\
Serum Na level & $-0.0517(p=0.009)$ & $-0.041(p=0.307)$ \\
Diastolic/Systolic HF & $-0.1863(p<0.001)$ & $-0.173(p<0.001)$ \\
Obesity & $-0.2959(p<0.001)$ & $-0.257(p<0.001)$ \\
\hline
\end{tabular}

Table 2 showed correlation coefficient and multivariate regression analysis of clinical variables that affected serum BNP levels in CHF patients. Results from correlation coefficient analysis showed weak-to-moderate correlation between BNP and four different clinical variables with statistical significant difference (obesity, serum BUN, Cr levels, and diastolic/systolic HF). Multivariate regression analysis was then performed with all 8 clinical variables together and showed moderate correlation effects only on two clinical variables (diastolic/systolic HF and obesity).

Table 3. Clinical information of CHF patients divided into four different groups by two clinical variables (obese versus non-obese and diastolic versus systolic $\mathrm{HF}$ ).

\begin{tabular}{|c|c|c|c|c|c|}
\hline \multirow[b]{2}{*}{ Number of patients } & \multicolumn{2}{|c|}{ Obese CHF patients } & \multicolumn{2}{|c|}{ Non-obese CHF patients } & \multirow{2}{*}{$\frac{p}{0.005}$} \\
\hline & $\begin{array}{c}\text { Diastolic HF } \\
N=145(55.8 \%)\end{array}$ & $\begin{array}{c}\text { Systolic HF } \\
N=115(44.2 \%)\end{array}$ & $\begin{array}{c}\text { Diastolic HF } \\
N=117(43.5 \%)\end{array}$ & $\begin{array}{c}\text { Systolic HF } \\
N=152(56.5 \%)\end{array}$ & \\
\hline $\mathrm{BNP}(\mathrm{pg} / \mathrm{dl})$ & $596.72 \pm 681.06$ & $805.09 \pm 694.45$ & $1034.72 \pm 1025.79$ & $1382.38 \pm 998.71$ & $<0.001$ \\
\hline $\begin{array}{l}\mathrm{Cr}(\mathrm{mg} / \mathrm{dl}) \\
\text { and its correlation with BNP } \\
\text { level (r) }\end{array}$ & $\begin{array}{l}1.73 \pm 1.38 \\
(r=0.5135)\end{array}$ & $\begin{array}{l}1.47 \pm 1.58 \\
(r=-0.0404)\end{array}$ & $\begin{array}{l}1.91 \pm 1.63 \\
(r=0.4317)\end{array}$ & $\begin{array}{l}1.66 \pm 2.41 \\
(r=0.1512)\end{array}$ & 0.315 \\
\hline $\begin{array}{l}\mathrm{BUN}(\mathrm{mg} / \mathrm{dl}) \\
\text { and its correlation with BNP } \\
\text { level (r) }\end{array}$ & $\begin{array}{l}25.16 \pm 16.24 \\
(r=0.2713)\end{array}$ & $\begin{array}{l}21.98 \pm 13.99 \\
(r=0.2751)\end{array}$ & $\begin{array}{l}27.75 \pm 20.26 \\
(r=0.2776)\end{array}$ & $\begin{array}{l}23.69 \pm 14.02 \\
(r=0.3606)\end{array}$ & 0.045 \\
\hline $\begin{array}{c}\text { LOH (Day) } \\
\text { and its correlation with BNP } \\
\text { level (r) }\end{array}$ & $\begin{array}{l}6.03 \pm 10.22 \\
(r=0.0678)\end{array}$ & $\begin{array}{l}5.79 \pm 9.52 \\
(r=0.0258)\end{array}$ & $\begin{array}{l}5.97 \pm 7.96 \\
(r=0.0666)\end{array}$ & $\begin{array}{l}4.43 \pm 3.58 \\
(r=-0.0739)\end{array}$ & 0.285 \\
\hline
\end{tabular}

Table 3 showed the comparison of BNP, Cr, BUN level and the length of hospitalization (LOH) in different CHF patient groups. The results showed more obese CHF patients had diastolic HF than non-obese CHF patients $(p=0.005)$. Diastolic HF patients had lower BNP level than systolic HF ones in both obese and non-obese groups $(p<0.001)$. Moderate-to-strong correlation was found between serum $\mathrm{Cr}$ and BNP levels in diastolic HF patients. 


\section{DISCUSSION}

$\mathrm{CHF}$ is a severe cardiovascular disease that requires regular clinical visits to maintain stability. Patients will usually seek care in the ED when decompensated. Serum BNP level is one of the serum markers that is usually ordered by ED physicians to further evaluate the CHF conditions. BNP plays an important role in the regulation of cardiac remodeling, ventricular stretching, vasodilatation, and sodium homeostasis $[12,13]$. Serum BNP levels usually will be elevated in patients with worsening CHF conditions. The results of some studies showed serum BNP level could be used as an independent clinical variable to predict the severity of CHF and suggested acutely decompensated CHF patients with higher serum BNP level needed to be treated aggressively $[14,15]$. Serum BNP level was also closely related to the mortality in CHF patients [16]. However, other studies showed the variability of serum BNP levels and were unable to predict the severity concisely in different CHF populations $[17,18]$. Some clinical variables which could affect the serum BNP level were evaluated in many studies before $[19,20]$. However, the results were quite controversial. Many variables were clinically dependent and thus could be acting as confounding factors [21]. Hence, in our study, 26 clinical variables were selected based on the results of previous studies and the relations between these variables and serum BNP level were analyzed together to determine the independent predictors thus avoiding the internal bias.

Our results showed serum BNP levels were inversely proportional to the severity of obesity which was consistent to the majority of previous studies $[8,17-18]$. Results from some studies showed lower serum adiponectin levels in obese patient and serum adiponectin correlated inversely with BMI. The hypoadiponectinemia stimulated cardiac remodeling and decreased stretching resulting in lower serum BNP level [22,23]. Visceral fat expansion also could increase the clearance of serum BNP by increasing the expression of clearance receptors on adipocytes [24]. In addition, ectopic lipid deposition in the heart may exert lipotoxic effect by altering cardiac lipid metabolism which could reduce the production of BNP in the cardiac ventricles as impaired cardiac function [25]. Overall, the mechanisms of lower serum BNP levels in obese CHF patients are multifactorial with resultant of several pathophysiological interactions.

Results from previous studies are controversial on whether lower serum BNP level is associated with diastolic HF. Some reported that left ventricular end diastolic wall stress was inversely associated with serum BNP level and BMI independently [26], while others showed positive or no correlation $[27,28]$. Our study found that diastolic HF patients had lower serum BNP levels than systolic HF patients in both obese and non-obese CHF groups. Furthermore, more obese patients had diastolic HF compared with non-obese CHF patients. When analyzed together, obesity and diastolic HF were two moderately stronger clinical variables that could affect the serum BNP levels.

Serum BNP level is also affected by renal function that reported in previous study [7]. In our study, serum BUN and Cr levels showed moderate correlation with BNP overall but strong correlation in diastolic HF patients. In our study, it seemed that chronic renal insufficiency occurred more often in diastolic $(40.46 \%, 106 /$ 262) compared with systolic HF patients $(32.58 \%, 87 /$ $267)$, yet no statistically significant difference reached ( $p$ $=0.06$ ). The results are consistent with recent study showing more diastolic HF occurred in chronic renal insufficiency patients [29]. Taking loop diuretics will cause lower serum $\mathrm{Na}$ level more often since $84.1 \%$ of hyponatremia patients in our study took loop diuretics which could make serum $\mathrm{Na}$ level as a confounding variable. Additionally, $87.05 \%$ (168/193) of patients with elevated serum $\mathrm{Cr}$ level and $90.45 \%$ (161/178) of patients with elevated serum BUN level took loop diuretics which could explain the weak correlation between loop diuretics and serum BNP level as well. Increased serum BNP levels in stroke and dementia patients were also reported in some studies though a weak correlation found $[30,31]$. However, studies were also found that the majority of stroke patients were hypertensive. By subdivideing stroke patients in groups with or without hypertension made no correlation with serum BNP levels [32]. Dementia patients usually have higher incidence of CVA or blood brain barrier disturbance resulting in higher BNP levels [33]. In addition, higher serum BNP levels are associated with impaired endothelial function which also linked to CVA and dementia as well [34]. In our study, these two clinical variables (history of CVA and dementia) showed weak correlations with serum BNP level and also hard to validate the accuracy due to relatively small sample size.

Some studies reported that prolonged hospitalization was found in CHF patients with higher serum BNP levels [11]. Our results showed poor correlation between serum BNP level and LOH in general. However, it seems that diastolic HF patients had higher serum $\mathrm{Cr}$ level and tended to stay longer in hospital than systolic HF patients though no statistically significant difference reached. This may attribute in part that more comorbidities found in diastolic HF patients in our study (data not shown).

Overall, in our study, the association between different clinical variables and serum BNP level were analyzed. High variability of serum BNP levels existed in CHF patients. Obesity and diastolic HF are two moderately stronger independent clinical predictors that could affect 
the serum BNP level. Hence, it is worthwhile to consider these predictors and to know the variability when interpreting BNP levels in different CHF patients.

\section{LIMITATION}

The retrospective methodology and relatively small sample size of our study may limit its applicability. In addition, using BMI to determine the obesity may not be very accurate since some CHF patients had signs and symptoms of volume overload that could affect the BMI. Other clinical variables that could potentially associated with serum BNP level were not included in this study, such as the ED revisits within 30 days, readmission within 30 days, intensive care units visit, the severity of pulmonary edema, etc. Follow-up was limited in many cases due to homelessness, incorrect registration information, or lack of access to communication devices. Overall, a large prospective study is required to confirm the effects of clinical variables on serum BNP levels in $\mathrm{CHF}$ patients.

\section{CONCLUSION}

Obesity and diastolic heart failure are two moderately stronger independent clinical variables that could affect the serum BNP level in CHF patients. Only in diastolic $\mathrm{HF}$ patients, serum $\mathrm{Cr}$ levels show moderate-to-strong correlation with serum BNP levels but not in systolic HF patients. In addition, serum BNP level is not a suitable clinical variable to predict the length of hospitalization in CHF patients. Therefore, it is recommended that physiccians should be cautious on interpreting BNP in different CHF populations.

\section{REFERENCES}

[1] Omland, T. and Hagve, T.A. (2009) Natriuretic peptides: Physiologic and analytic considerations. Heart Failure Clinics, 5, 471-487. doi:10.1016/j.hfc.2009.04.005

[2] Maisel, A. and Mehra, M.R. (2005) Understanding Btype natriuretic peptide and its role in diagnosing and monitoring congestive heart failure. Clinical Cornerstone, 7, S7-S17. doi:10.1016/S1098-3597(05)80009-2

[3] Popescu, B.A., Popescu, A.C., Antonini-Canterin, F., Rubin, D., Cappelletti, P., Piazza, R., Ginghina, C., Dimulescu, D., Beladan, C.C. and Nicolosi, G.L. (2007) Prognostic role of left atrial volume in elderly patients with symptomatic stable chronic heart failure: Comparison with left ventricular diastolic dysfunction and B-type natriuretic peptide. Echocardiography, 24, 1035-1043. doi:10.1111/j.1540-8175.2007.00540.x

[4] de Denus, S., Pharand, C. and Williamson, D.R. (2004) Brain natriuretic peptide in the management of heart failure: The versatile neurohormone. Chest, 125, 652-668. doi:10.1378/chest.125.2.652

[5] Wiley, C.L., Switzer, S.P., Berg, R.L., Glurich, I. and Dart, R.A. (2010) Association of B-type natriuretic pep- tide levels with estimated glomerular filtration rate and congestive heart failure. Clinical Medicine Research, 8, 7-12. doi:10.3121/cmr.2009.867

[6] Krauser, D.G., Lloyd-Jones, D.M., Chae, C.U., Cameron, R., Anwaruddin, S., Baggish, A.L., Chen, A., Tung, R. and Januzzi, J.L. Jr. (2005) Effect of body mass index on natriuretic peptide levels in patients with acute congestive heart failure: A ProBNP investigation of dyspnea in the emergency department (PRIDE) substudy. American Heart Journal, 149, 744-750. doi:10.1016/j.ahj.2004.07.010

[7] Anwaruddin, S., Lloyd-Jones, D.M., Baggish, A., Chen, A., Krauser, D., Tung, R., Chae, C. and Januzzi, J.L. Jr. (2006) Renal function, congestive heart failure, and aminoterminal pro-brain natriuretic peptide measurement: Results from the ProBNP Investigation of dyspnea in the emergency department (PRIDE) study. Journal of the American College of Cardiology, 47, 91-97. doi:10.1016/j.jacc.2005.08.051

[8] McCord, J., Mundy, B.J., Hudson, M.P., Maisel, A.S., Hollander, J.E., Abraham, W.T., Steg, P.G., Omland, T., Knudsen, C.W., Sandberg, K.R. and McCullough, P.A. (2004) Relationship between obesity and B-type natriuretic peptide levels. Archives of Internal Medicine, 164, 2247-2252. doi:10.1001/archinte.164.20.2247

[9] Maeder, M.T., Mariani, J.A. and Kaye, D.M. (2010) Hemodynamic determinants of myocardial B-type natriuretic peptide release: Relative contributions of systolic and diastolic wall stress. Hypertension, 56, 682-689. doi:10.1161/HYPERTENSIONAHA.110.156547

[10] Hedley, A.A., Ogden, C.L., Johnson, C.L., Carroll, M.D., Curtin, L.R. and Flegal, K.M. (2004) Prevalence of overweight and obesity among US children, adolescents, and adults, 1999-2002. Archives of Internal Medicine, 291, 2847-2850. doi:10.1001/jama.291.23.2847

[11] Valle, R. and Aspromonte, N. (2010) Use of brain natriuretic peptide and bioimpedance to guide therapy in heart failure patients. Contributions to Nephrology, 164, 209216. doi: $10.1159 / 000313732$

[12] Palazzuoli, A., Gallotta, M., Quatrini, I. and Nuti, R. (2010) Natriuretic peptides (BNP and NT-ProBNP): Measurement and relevance in heart failure. Vascular Health and Risk Management, 6, 411-418. doi:10.2147/VHRM.S5789

[13] Krupicka, J., Janota, T., Kasalová, Z. and Hradec, J. (2009) Natriuretic peptides-Physiology, pathophysiology and clinical use in heart failure. Physiological Research, 58, 171-177.

[14] Heist, E.K. and Ruskin, J.N. (2006) Atrial fibrillation and congestive heart failure: Risk factors, mechanisms, and treatment. Progress in Cardiovascular Diseases, 48, 256269. doi:10.1016/j.pcad.2005.09.001

[15] Lang, C.C. and Mancini, D.M. (2007) Non-cardiac comorbidities in chronic heart failure. Heart, 93, 665-671. doi:10.1136/hrt.2005.068296

[16] Cicoira, M., Maggioni, A.P., Latini, R., Barlera, S., Carretta, E., Janosi, A., Soler Soler, J., Anand, I., Cohn, J.N. (2007) Body mass index, prognosis and mode of death in chronic heart failure: Results from the Valsartan Heart Failure Trial. European Journal of Heart Failure, 9, 397- 
402. doi:10.1016/j.ejheart.2006.10.016

[17] Frankenstein, L., Zugck, C., Nelles, M., Schellberg, D., Katus, H.A. and Remppis, B.A. (2009) The obesity paradox in stable chronic heart failure does not persist after matching for indicators of disease severity and confounders. European Journal of Heart Failure, 11, 1189-1194. doi:10.1093/eurjhf/hfp150

[18] Oreopoulos, A., Padwal, R., Kalantar-Zadeh, K., Fonarow, G.C., Norris, C.M. and McAlister, F.A. (2008) Body mass index and mortality in heart failure: A meta-analysis. American Heart Journal, 156, 13-22. doi:10.1016/j.ahj.2008.02.014

[19] Stolker, J.M. and Rich, M.W. (2010) Clinical utility of B-type natriuretic peptide for estimating left ventricular filling pressures in unselected elderly patients undergoing diagnostic coronary angiography. Journal of Invasive Cardiology, 22, 107-112.

[20] Adlam, D., Silcocks, P. and Sparrow, N. (2005) Using BNP to develop a risk score for heart failure in primary care. European Heart Journal, 26, 1086-1093. doi:10.1093/eurheartj/ehi178

[21] Codognotto, M., Piccoli, A., Zaninotto, M., Mion, M., Plebani, M., Vertolli, U., Tona, F., Ruzza, L., Barchita, A. and Boffa, G.M. (2007) Renal dysfunction is a confounder for plasma natriuretic peptides in detecting heart dysfunction in uremic and idiopathic dilated cardiomyopathies. Clinical Chemistry, 53, 2097-2104. doi:10.1373/clinchem.2007.089656

[22] Trimarchi, H., Muryan, A., Dicugno, M., Forrester, M., Lombi, F., Young, P., Pomeranz, V., Iriarte, R., Barucca, N., Campolo-Girard, V., Alonso, M. and Lindholm, B. (2011) In hemodialysis, adiponectin, and pro-brain natriuretic peptide levels may be subjected to variations in body mass index. Hemodialysis International, 15, 477484. doi:10.1111/j.1542-4758.2011.00562.x

[23] Selthofer-Relatić, K., Radić, R., Vcev, A., Steiner, R., Vizjak, V., Sram, M., Tripolski, M., Kosović, P., Bosnjak, I. and Selthofer, R. (2011) Low adiponectin serum level-reduced protective effect on the left ventricular wall thickness. Collegium of Antropologicum, 35, 787-791.

[24] Clerico, A., Giannoni, A., Vittorini, S. and Emdin, M. (2012) The paradox of low BNP levels in obesity. Heart Failure Reviews, 17, 81-96.

[25] Polak, J., Kotrc, M., Wedellova, Z., Jabor, A., Malek, I., Kautzner, J., Kazdova, L. and Melenovsky, V. (2011) Lipolytic effects of B-type natriuretic peptide 1-32 in adipose tissue of heart failure patients compared with healthy controls. Journal of the American College of Cardiology, 58, 1119-1125.

\section{doi:10.1016/j.jacc.2011.05.042}

[26] Iwanaga, Y., Kihara, Y., Niizuma, S., Noguchi, T., Nonogi, H., Kita, T. and Goto, Y. (2007) BNP in overweight and obese patients with heart failure: an analysis based on the BNP-LV diastolic wall stress relationship. Journal of Cardiac Failure, 13, 663-667. doi:10.1016/j.cardfail.2007.05.002

[27] Niizuma, S., Iwanaga, Y., Yahata, T., Tamaki, Y., Goto, Y., Nakahama, H. and Miyazaki, S. (2009) Impact of left ventricular end-diastolic wall stress on plasma B-type natriuretic peptide in heart failure with chronic kidney disease and end-stage renal disease. Clinical Chemistry, 55, 1347-1353. doi:10.1373/clinchem.2008.121236

[28] Tosa, S., Watanabe, H., Iino, K., Terui, G., Kosaka, T., Hasegawa, H. and Ito, H. (2009) Usefulness of plasma BNP levels as a marker of left ventricular wall stress in obese individuals. International Heart Journal, 50, 173182. doi:10.1536/ihj.50.173

[29] Victor, B.M. and Barron, J.T. (2010) Diastolic heart failure versus diastolic dysfunction: Difference in renal function. Clinical Cardiology, 33, 770-774. doi:10.1002/clc.20824

[30] Saritas, A., Cakir, Z., Emet, M., Uzkeser, M., Akoz, A. and Acemoglu, H. (2009) Factors affecting the B-type natriuretic peptide levels in stroke patients. Annals Academy of Medicine Singapore, 39, 385-389.

[31] Kondziella, D., Göthlin, M., Fu, M., Zetterberg, H. and Wallin, A. (2009) B-type natriuretic peptide plasma levels are elevated in subcortical vascular dementia. $\mathrm{Neu}$ roReport, 20, 825-827. doi:10.1097/WNR.0b013e328326f82f

[32] Cakir, Z., Saritas, A., Emet, M., Aslan, S., Akoz, A. and Gundogdu, F. (2010) A prospective study of brain natriuretic peptide levels in three subgroups: Stroke with hypertension, stroke without hypertension, and hypertension alone. Annals of Indian Academy of Neurology, 13, 47-51. doi:10.4103/0972-2327.61277

[33] Kerola, T., Nieminen, T., Hartikainen, S., Sulkava, R., Vuolteenaho, O. and Kettunen, R. (2010) B-type natriuretic peptide as a predictor of declining cognitive function and dementia: A cohort study of an elderly general population with a 5-year follow-up. Annals of Medicine, 42, 207-215. doi:10.3109/07853891003652542

[34] Gunstad, J., Poppas, A., Smeal, S., Paul, R.H., Tate, D.F., Jefferson, A.L., Forman, D.E. and Cohen, R.A. (2006) Relation of brain natriuretic peptide levels to cognitive dysfunction in adults $>55$ years of age with cardiovascular disease. American Journal of Cardiology, 98, 538-540. doi:10.1016/j.amjcard.2006.02.062 